\title{
Analysis of Characteristics of Meteorological Elements in An Aircraft icing Case
}

\author{
Xu Ting, Wu Junjie and Feng wan
}

Civil Aviation Flight University of China, Guanghan 618307, Ch ina

Keywords: aircraft icing, southern branch trough, icing index

\begin{abstract}
This paper includes an analysis of an aircraft icing case occurred near Suining Airport in 6, March, 2015. It shows that southern branch trough associated with cyclone at the east of trough is the background of this aircraft icing case. Southwest steam in front of the southern branch trough transports the warm and wet air to Sichuan basin, and cold air in back of cyclone uplifts the warm and wet air. Aircraft icing occurred near the cold advection side of the intersection area of cold advection and warm advection, this area has weak upward air current. Icing index recommended by International Civil Aviation Organization is a great implication in this case.
\end{abstract}

\section{Introduction}

Aircraft icing refers to phenomenon that ice gathered in some places of an aircraft. It may be caused by super cooled water in clouds or precipitation, super cooled water bump aircraft and froze quickly. Sublimation of water vapor near the aircraft can also cause aircraft icing [1]. In flight aircraft icing will deterioration the aerodynamic performance of aircraft, decrease the lift, increase the drag. Aircraft icing may influence the stability and maneuverability, cause communication interruption and instrument failure, and even cause aircraft crash. In recent years, speed and altitude of flight have significantly improved, and anti-icing and deicing equipments are maturing, aircraft icing has fewer affect to flight than past. But during low speed flight phase, aircraft icing is also dangerous.

Wang et al. [2] use the 40 years (1958-1997) re-analysis data processed by National Center for Environmental Prediction (NCEP) and National Center for Atmospheric Research (NCAR) to construct an icing index, and analyst climatic characteristics of aircraft icing in China. It shows that Sichuan basin is an aircraft icing prone area. Li [3] points that front weather associated with trough line or shear line is a major weather system in aircraft icing cases. Cold front move southward form Hetao area, cold air move from south of Shanxi to Sichuan basin, and cause aircraft icing. Researches [4, 5] indicate that aircraft icing appear when the temperature is between $-15^{\circ} \mathrm{C}$ to $0^{\circ} \mathrm{C}$. Feeble icing appear frequently at $-12^{\circ} \mathrm{C}$ to $0^{\circ} \mathrm{C},-12^{\circ} \mathrm{C}$ to $-2^{\circ} \mathrm{C}$ for moderate icing and $-10^{\circ} \mathrm{C}$ to $-8^{\circ} \mathrm{C}$ for severe icing respectively. Humidity condition for aircraft icing is that difference between temperature and dew point is less than $7^{\circ} \mathrm{C}$, especially less than $4^{\circ} \mathrm{C}$. Jin et al. [6] point that the possibility of aircraft icing is high when the aircraft is descending and decelerating. This paper makes an analysis of an aircraft icing case occurred near the Suining airport $\left(105.05^{\circ} \mathrm{E}, 30.5^{\circ} \mathrm{N}\right)$, an airport mainly for flight training in southwest of China, 0036UTC in 6th, March, 2015. Reanalysis data are used to analyze the characteristics of temperature, humidity, temperature advection and vertical current, and analyze the indication of icing index in this case. 


\section{Data}

Data used in this paper is the reanalysis data from European Centre for Medium-Range Weather Forecast (ECMWF), named ERA-Interim. This global reanalysis data ranges from 1979 to present and it is produced with a 2006 version of the IFS (Cy31r2) and continues to be updated in real time [7]. The horizontal resolution of ERA-Interim is $1^{\circ} \times 1^{\circ}$. This reanalysis data has 37 vertical layers from $1000 \mathrm{hPa}$ to $1 \mathrm{hPa}$. This reanalysis data has four records in one day: 0000UTC, 0600UTC, 1200UTC and 1800UTC. In this article, 000UTC in 6th, March, 2015 is used to analyze the characteristics of meteorological elements.

\section{Background of Aircraft Icing}

Surface weather chart of 0000UTC in 6th, March, 2015 (picture omitted) show that the pressure is low at east of Sichuan Basin, cold air from Hetao Area move southward along east side of the Tibet Plateau. In the mean time, southwesterly wind in the southern branch trough above Sichuan Basin and northerly wind of back of the cyclone located in the east of basin converge and uplift. Fig 1 show that Suining Airport is in the convergence area and warm southwesterly wind bring abundant water vapor to Suining. In the condition of warm and moist, aircraft icing will appear at certain altitude. The southern branch trough associated with cyclone at the east of trough is the background of this aircraft icing case.

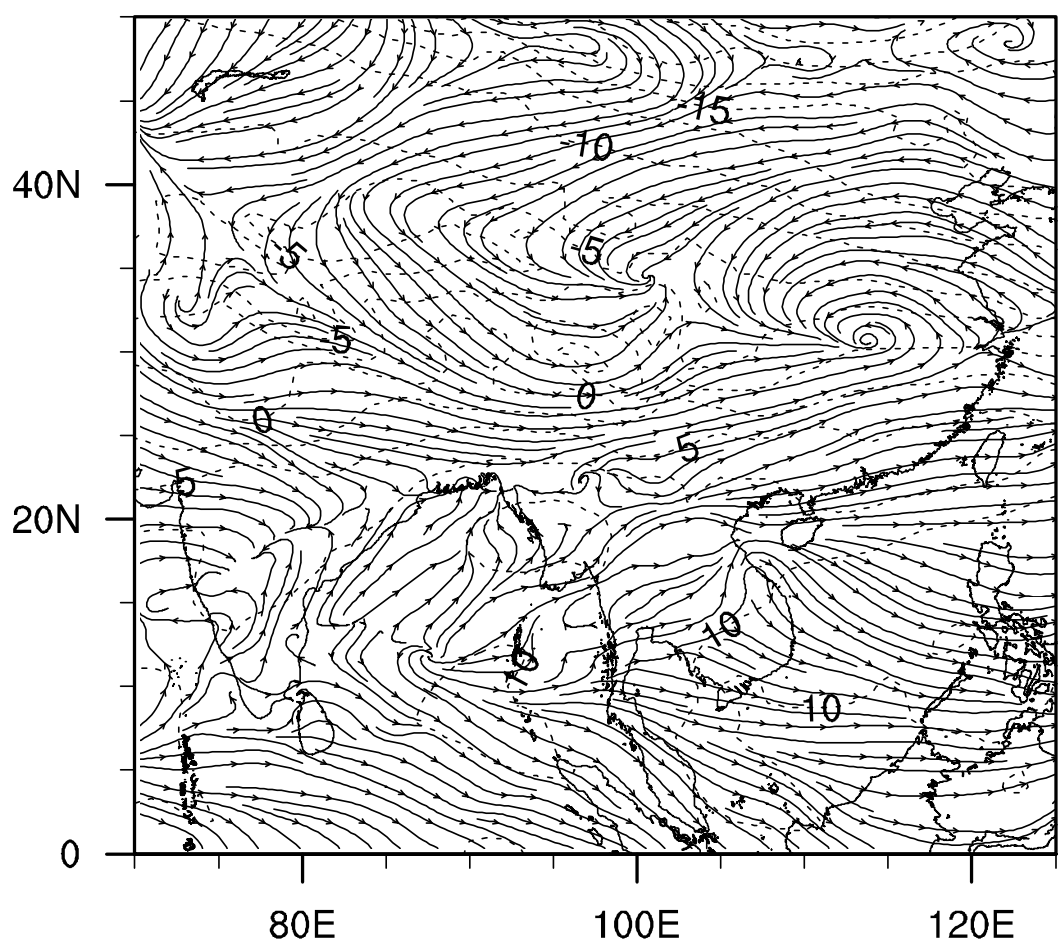

Fig.1 Stream field (solid line and vector, unit: $\mathrm{m} / \mathrm{s}$ ) and temperature (dotted line, unit: ${ }^{\circ} \mathrm{C}$ ) at

700hPa of 0000UTC, 6th, March, 2015

\section{Physical Diagnosis}

Temperature, Moisture and Vertical Current in Middle and Low Level. In order to obtain the characteristics of temperature, moisture and vertical current, reanalysis data of 0000UTC are used. Temperature - humidity profile (Fig.2) and vertical current - temperature advection profile (Fig.3) are drawn along $105^{\circ} \mathrm{E}$. It shows that there is a cold tongue extending to south in lower 
troposphere between $26^{\circ} \mathrm{N}$ and $33^{\circ} \mathrm{N}$. Suining Airport are under the control of the cold tongue, temperature at $700 \mathrm{hPa}$ is about $-4^{\circ} \mathrm{C}$, and $-1^{\circ} \mathrm{C}$ at $850 \mathrm{hPa}$. The temperature condition are beneficial to form aircraft icing. In the mean time, an moist area extending from south to north is above the cold tongue. Altitude of the center line of this moist area are increased with latitude, and Sichuan Basin are located in an moist area, reaching 3-4 g. kg-1. This indicates that warm and moist air are uplifting by the cold air from north.

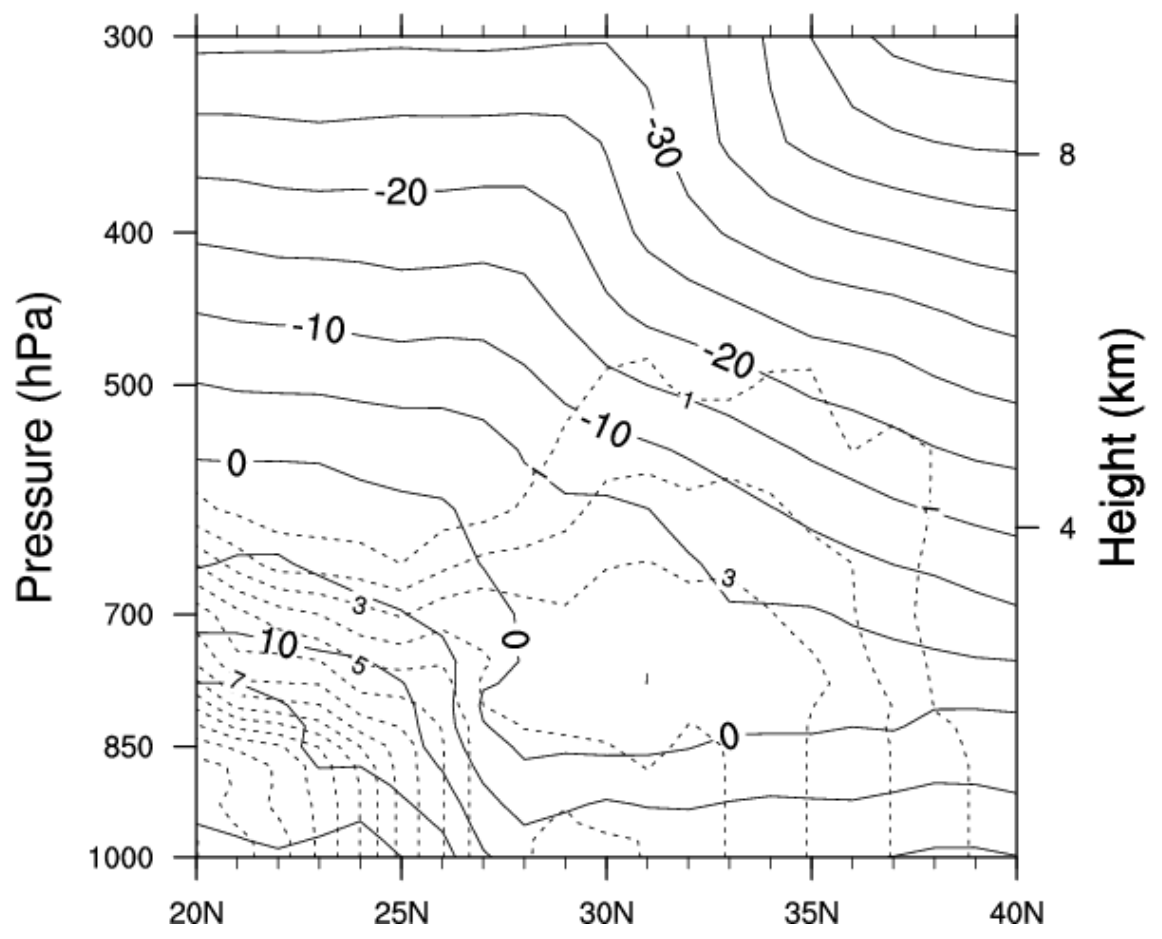

Fig.2 Profile of temperature (solid line, unit: ${ }^{\circ} \mathrm{C}$ ) and specific humidity (dotted line, unit: g/kg) along $105^{\circ} \mathrm{E}$ at $700 \mathrm{hPa}$ of $0000 \mathrm{UTC}$, 6th, March, 2015

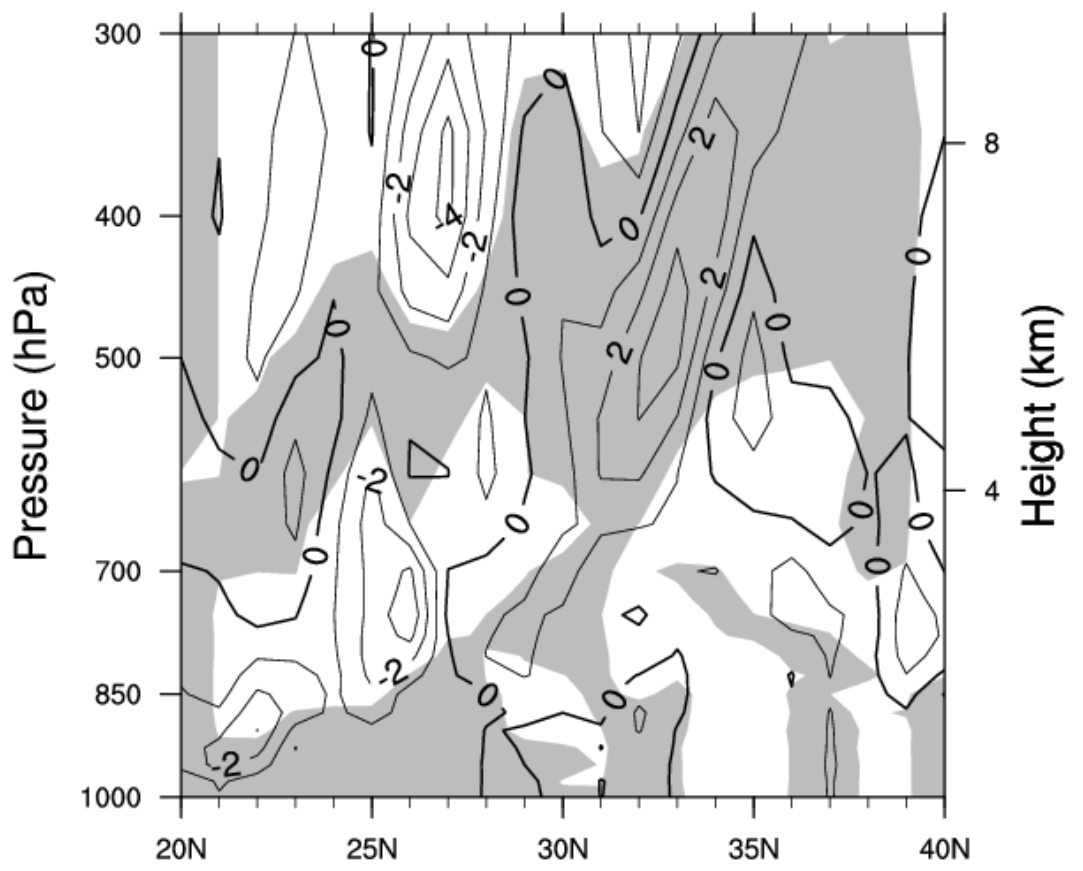

Fig.3 Profile of vertical speed (solid line, unit: $10^{-1} \mathrm{~Pa}^{-1} \mathrm{~s}^{-1}$ ) and temperature advection (shading for warm advection and no shading for cold advection) along $105^{\circ} \mathrm{E}$ at $700 \mathrm{hPa}$ of $0000 \mathrm{UTC}$, 6th, 
Aircraft Icing Index. Aircraft icing index is an index to indicate what area will occur aircraft icing effectively which recommended by the International Civil Aviation Organization [8]. Aircraft icing index can be expressed as followed, $\mathrm{I}_{\mathrm{c}}=\{[(\mathrm{RH}-50) \times 2] \times[\mathrm{T} \times(\mathrm{T}+14) \div(-49)]\} \div$ $10, \mathrm{RH}$ for relative humidity, $\mathrm{T}$ for temperature. When the aircraft icing index is positive indicates there is potential icing area. And larger the aircraft icing index is, the greater likelihood of icing occurrence. The first half of aircraft icing index represent the amount and size of water drop, with the relative humidity ranging from $50 \%$ to $100 \%$, aircraft icing index ranges from 0 to 10 . The last half of the formula indicates the increase rate by using square of temperature, the maximum of this part will occur when $\mathrm{T}=-7^{\circ} \mathrm{C}$. When the temperature is between $0^{\circ} \mathrm{C}$ and $-14^{\circ} \mathrm{C}$, aircraft icing index is negative, icing can hardly happen.

Fig.4 is the distribution of aircraft icing index recommended by the International Civil Aviation Organization at 0000UTC, 6th, March, 2015. Fig.4 shows that the aircraft icing index of Sichuan Basin is high which indicates icing will occur. Suining airport $\left(105.05^{\circ} \mathrm{E}, 30.5^{\circ} \mathrm{N}\right)$ is located in this high index region and it is consistent with the actual situation.

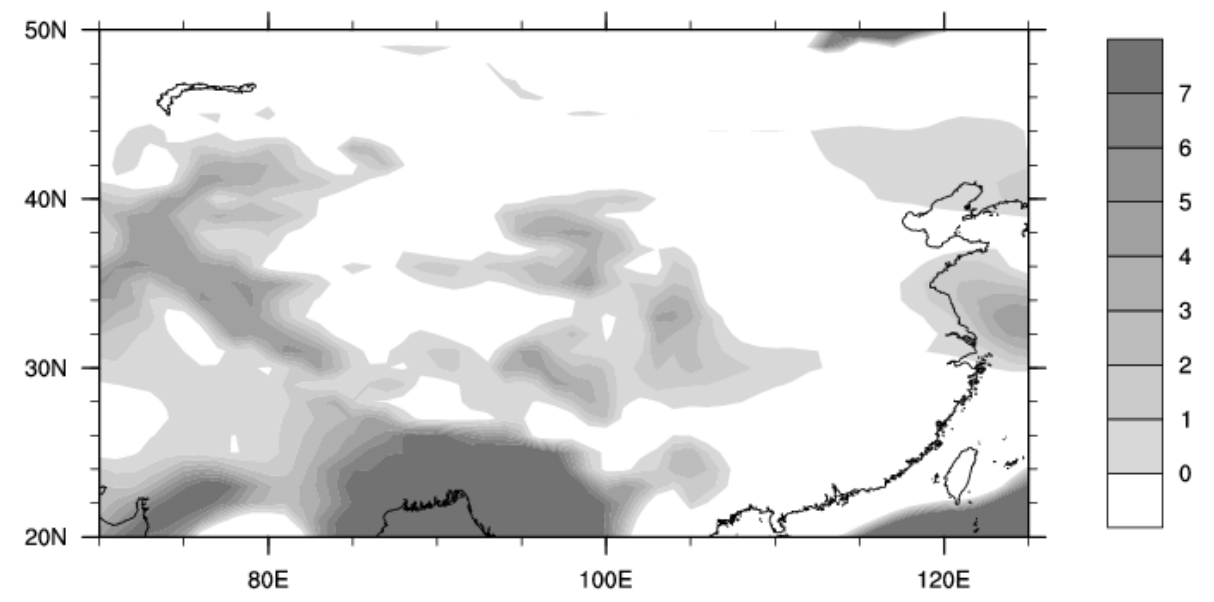

Fig.4 Distribution of aircraft icing index at 0000UTC, 6th, March, 2015

\section{Conclusions}

(1) Southern branch trough associated with cyclone at the east of trough is the background of this aircraft icing case. Southwest steam in front of the southern branch trough transports the warm and wet air to Sichuan basin, and cold air in back of cyclone uplifts the warm and wet air.

(2) Aircraft icing occurred near the cold advection side of the intersection area of cold advection and warm advection, this area has weak upward air current.

(3) Icing index recommended by International Civil Aviation Organization is a great implication in this case.

(4) These results are obtained by a case analysis. They are of importance for us to further understand the conditions of aircraft icing in Sichuan Basin, but it is eager to have more cases to certify the universality of these results.

\section{Acknowledgements}

The financial support of Youth Foundation of Civil Aviation Flight University of China, grant Q2014-066 and Priority Project Foundation of Civil Aviation Flight University of China, grant ZJ2014-02 is appreciated. 


\section{Reference}

[1] Huang Yifang. Aviation Meteorology [M]. Southwest Jiaotong University Press, 2011: 145-147. (In Chinese)

[2] Wang Xinwei, Zhang Jun. Climatic Features of Aircraft Icing of China [J]. Journal of the Meteorological Sciences, 2002, 22(3): 343-350. (In Chinese)

[3] Li Ziliang. Analysis of Meteorological Characteristics of Aircraft Icing [J]. Journal of Sichuan Meteorology, 1999, 9(3): 56-57. (In Chinese)

[4] Li Ziliang, Pan Weiduo. Applied Software on the Forecasting Aircraft Icing [J]. Meteorological Monthly, 1996, 22(12): 17-19. (In Chinese)

[5] Zhao Shuhai. Aviation Meteorology [M]. China Meteorological Press, 1994: 190-191. (In Chinese)

[6] Jin Weiming, Wang Bingren. A Preliminary Study on the Cause of Aircraft Engine Icing [J]. Meteorological Monthly, 1997, 23(2): 8-11. (In Chinese)

[7] Dee D P, Uppala S M, Simmons A J, et al. The ERA - Interim reanalysis: Configuration and performance of the data assimilation system[J]. Quarterly Journal of the Royal Meteorological Society, 2011, 137(656): 553-597.

[8] Carrière J M, Alquier S, Bot C L, et al. Statistical verification of forecast icing risk indices[J]. Meteorological Applications, 1997, 4(02): 115-130. 